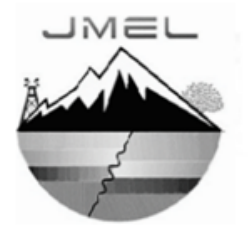

\title{
Konservasi Mataair untuk Memenuhi Kebutuhan Domestik di Daerah Desa Pagerharjo, Kecamatan Samigaluh, Kabupaten Kulon Progo, Daerah Istimewa Yogyakarta
}

\author{
Lica Nurmasita $^{1, \mathrm{a})}$ Rr. Dina Asrifah ${ }^{1, \mathrm{~b})}$ Dian Hudawan Santoso ${ }^{1, \mathrm{c})}$ \\ 1) Jurusan Teknik Lingkungan, Fakultas Teknologi Mineral, UPN "Veteran" Yogyakarta \\ JL. SWK 104 Condong Catur, Depok Sleman, Yogyakarta

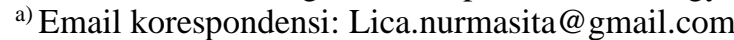 \\ b) dina_asrifah@upnyk.ac.id ${ }^{\text {c) }}$ dian.hudawan@upnyk.ac.id
}

\begin{abstract}
ABSTRAK
Desa Pagerharjo, Kecamatan Samigaluh, Kabupaten Kulon Progo salah satu wilayah yang diprediksi sebagai daerah tingkat ancaman kekeringan tinggi menurut Peta Ancaman Kekeringan Kabupaten Kulon Progo. Pemenuhan kebutuhan air bersih berasal dari Mataair Tuk Wadang, Kali Lo, Kali Gandu, Kali Bajing dan Bulusari. Mataair di Desa Pagerharjo perlu dilakukan konservasi agar pemanfaatannya lebih efektif. Penelitian ini bertujuan untuk mengkaji potensi mataair agar dapat ditentukan teknik konservasinya. Penelitian berada di Desa Pagerharjo, Kecamatan Samigaluh, Kabupaten Kulon Progo yang dilakukan pada bulan Februari hingga November 2019. Metode yang digunakan antara lain metode matematis, metode laboratorium, metode wawancara dan metode analisis statistik. Metode laboratorium mengacu pada Peraturan Gubernur DIY No. 20 Tahun 2008 untuk mengetahui kualitas air. Hasil yang diperoleh menunjukkan debit mataair dapat memenuhi kebutuhan penduduk hingga 10 tahun kedepan. Kualitas mataair cukup baik namun melebihi baku mutu untuk parameter COD pada Mataair Kali Lo dan Bulusari serta parameter total koliform pada Mataair Tuk Wadang, Kali Lo, Kali Gandu dan Bulusari. Kualitas air menurun seiring pertumbuhan penduduk tetapi dapat diatasi dengan arahan konservasi. Arahan konservasi dengan pembuatan teras individu dan penanaman rumput gajah paitan, pembuatan bangunan penangkap mataair, bak penampung dengan kapasitas $2 \mathrm{~m}^{3}$ dan $5 \mathrm{~m}^{3}$, pendekatan sosial dan pendekatan pemerintah.
\end{abstract}

Kata Kunci: konservasi; mataair; potensi

\section{ABSTRACT}

Pagerharjo, Samigaluh, Kulon Progo is areas has been predicted with a high level of drought threat based on Map of Kulon Progo Regency Drought Threat. Inhabitants needs of water came from springs Tuk Wadang, Kali Lo, Kali Gandu, Kali Bajing and Bulusari. The springs in Pagerharjo Village needs to be conserved. This research aimed to study the potential of springs to be determined in conservation techniques. This study was located in Pagerharjo, Samigaluh, Kulon Progo, and conducted from February to November 2019. The methods used were mathematical, laboratory, interview and statistical analysis. Laboratory method based on Special Region of Yogyakarta's Governor's Regulations Number 20 in the year of 2008. The results indicated that the potential quantity of springs will meet the needs of population in 10 years. The quality of water springs are good, but there are exceeds the quality standard parameters is COD in the Kali Lo and Bulusari and total coliform in the Tuk Wadang, Kali Lo, Kali Gandu and Bulusari. The quality of water decreased along with population's growth, but it could be solved with conservation. The direction of conservation is by making individual terraces and planting grass, constructing springs catching structures, reservoirs with capacity $2 \mathrm{~m}^{3}$ and $5 \mathrm{~m}^{3}$, socialand government approaches.

Keywords: conservation; potential; springs

\section{PENDAHULUAN}

\subsection{Latar Belakang}

Pemanasan global selama abad terakhir telah mengakibatkan perubahan iklim yang telah menjadi isu paling penting dalam kebijakan pembangunan pada abad ke-21 (Rasmikayati dan Endah, 2015). Penelitian mengenai pengaruh pemanasan global terhadap perubahan musim di Pulau Jawa menunjukkan bahwa dalam 40 tahun mendatang, awal musim hujan akan mengalami kemunduran sedangkan akhir musim hujan akan lebih pendek. Sementara curah hujan musim hujan cenderung meningkat sedangkan curah hujan musim kemarau cenderung menurun. Hal ini menunjukkan semakin meningkatnya risiko kekeringan di musim kemarau dan risiko banjir atau bahaya longsor pada musim hujan (Efendi, 2012). Ancaman kekeringan ini dapat mempengaruhi kemunculan air di mataair. 
Air merupakan salah satu unsur alam yang sangat dibutuhkan dalam keberlangsungan kehidupan makhluk hidup khususnya manusia (Admadhani, 2014). Pemenuhan kebutuhan air untuk daerah pedesaan umumnya berasal dari mataair, sumur gali ataupun sungai. Kebutuhan air semakin meningkat seiring dengan pertumbuhan penduduk di Indonesia. Selain untuk aktivitas di masing-masing rumah tangga, air juga diperlukan untuk fasilitas umum dan perkebunan. Pendistribusian sumberdaya air harus diperhatikan agar kebutuhan air warga dapat terpenuhi. Desa Pagerharjo, Kecamatan Samigaluh, Kabupaten Kulon Progo merupakan salah satu wilayah yang diprediksi sebagai daerah dengan tingkat ancaman kekeringan tinggi berdasarkan peta ancaman kekeringan Kabupaten Kulon Progo. Pemenuhan kebutuhan air bersih warga Desa Pagerharjo berasal dari mataair yang tersebar di beberapa lokasi di Desa Pagerharjo, karena hanya beberapa warga yang memiliki sumur. Pengelolaan atau konservasi mataair yang kurang maksimal menyebabkan beberapa debit mataair berkurang ketika musim kemarau sehingga menyebabkan pengambilan air dari mataair harus dilakukan dengan cara bergantian untuk pemenuhan kebutuhan air warga. Kualitas air di daerah ini juga perlu diuji supaya pemenuhan kebutuhan air warga dapat tercukupi dengan kualitas yang baik.

Perlu dilakukan penelitian mengenai potensi mataair di Desa Pagerharjo karena adanya permasalahan yang sudah dijelaskan diatas. Selanjutnya dilakukan pengujian terhadap kualitas mataair yang digunakan warga. Berbagai informasi yang sudah didapat, selanjutnya digunakan sebagai dasar untuk menentukan arahan pengelolaan yang tepat untuk mataair Tuk Wadang, Kali Lo, Kali Gandu, Kalibajing, dan Bulusari di daerah Desa Pagerharjo. Berdasarkan hal tersebut maka penulis tertarik untuk melakukan penelitian terkait "Konservasi Mataair untuk Memenuhi Kebutuhan Domestik di Daerah Desa Pagerharjo, Kecamatan Samigaluh, Kabupaten Kulon Progo, Daerah Istimewa Yogyakarta.”

\subsection{Tujuan}

Tujuan penelitian sebagai berikut:

1. Mengkaji potensi (kualitas dan kuantitas) mataair untuk memenuhi kebutuhan domestik sampai 10 tahun kedepan di daerah penelitian.

2. Menentukan arahan konservasi mataair untuk mempertahankan ketersediaan air di daerah penelitian.

\section{METODE}

Daerah penelitian secara astronomis berada pada koordinat UTM (Universal Transverse Mercator) 403304 - 405738 mT dan 9150570 - 9153842 mU, sedangkan secara administratif daerah penelitian berada di sebagian Desa Pagerharjo, Kecamatan Samigaluh, Kabupaten Kulon Progo, Daerah Istimewa Yogyakarta. Lokasi daerah penelitian dapat dilihat pada Gambar 1. dengan luasan daerah penelitian yaitu 473,95 Ha. Penelitian dilaksanakan pada bulan Februari hingga November 2019. Alat yang digunakan dalam penelitian ini berupa peta dan data pendukung, GPS, kompas, palu geologi, meteran, bola pingpong, stopwatch dan jerigen.

Penelitian dilakukan dengan metode matematis, metode laboratorium, metode wawancara dan metode analisis statistik. Metode matematis untuk mengolah data mataair yang dikaji berupa kualitas dan kuantitas mataair selama 10 tahun kedepan. Metode laboratorium digunakan untuk mengetahui kualitas air parameter kekeruhan, TDS, pH, BOD, COD, nitrat, besi dan total koliform. Metode wawancara digunakan untuk mencari informasi dari masyarakat pengguna mataair. Parameter mataair mengacu pada Peraturan Gubernur DIY No. 20 Tahun 2008. Metode analisis statistik untuk mendapatkan kesimpulan dari data yang didapat berupa arahan konservasi. 


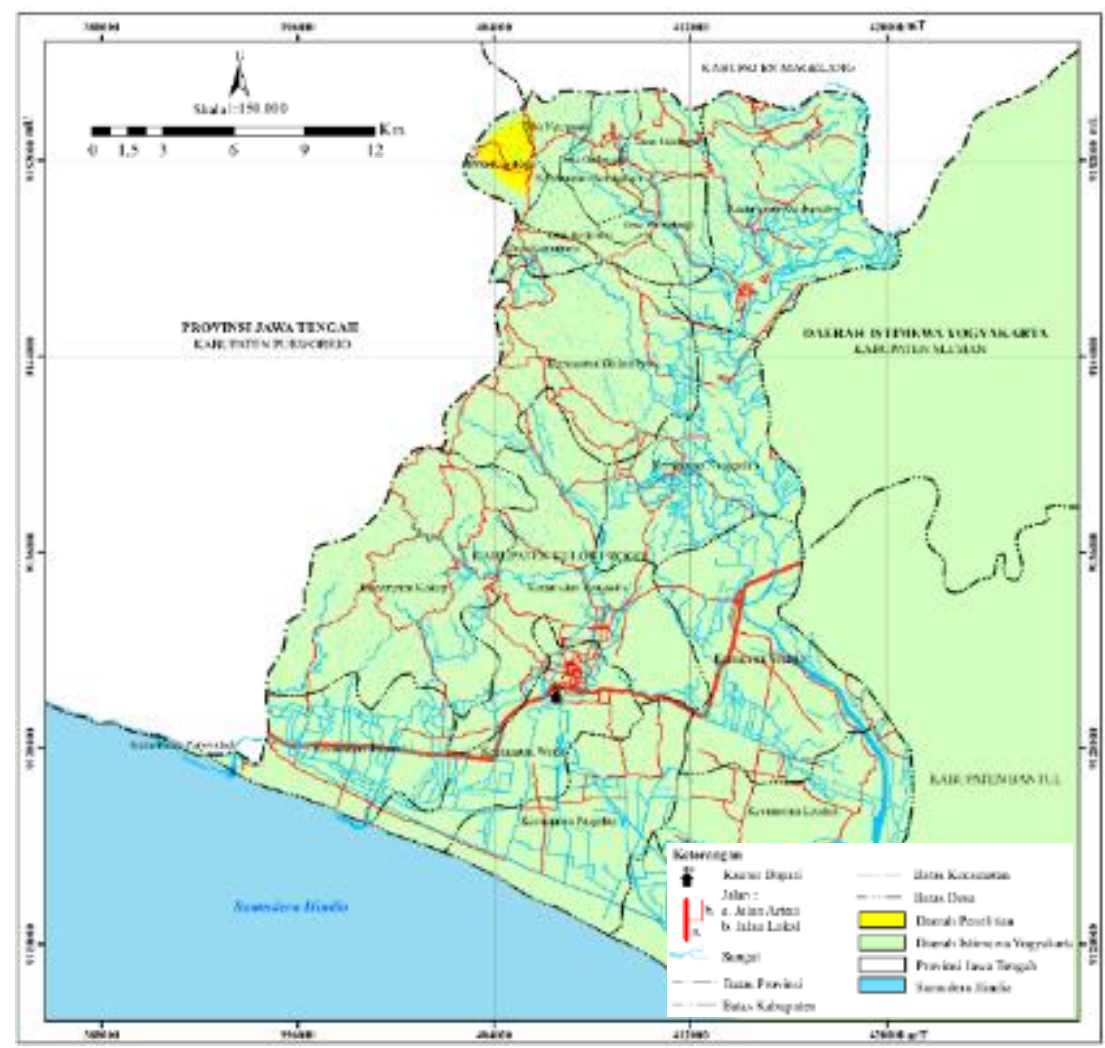

Gambar 1. Peta Administrasi Daerah Penelitian (Sumber: Peta Rupa Bumi Indonesia)

Tahapan penelitian diawali dengan tahap lapangan yaitu pengukuran debit dan pengambilan sampel air. Debit mataair dilakukan pengukuran untuk mengetahui ketersediaan air untuk memenuhi kebutuhan domestik. Prinsip pengukuran debit metaair menggunakan metode volumetrik dan metode manning berdasarkan Lampiran Peraturan Menteri Pekerjaan Umum No. 18 Tahun 2007 tentang Penyelenggaraan Pengembangan Sistem Penyediaan Air Minum yang dapat dilihat pada Persamaan 1 dan Persamaan 2. Pengukuran debit mataair dilakukan pada Bulan Februari hingga November 2019. Rumus volumetrik pengukuran debit digunakan untuk Mataair Tuk Wadang, Kali Gandu dan Kali Bajing karena mataair tersebut terdapat penampung air.

$$
\mathrm{Q}=\frac{\mathrm{HxA}}{\mathrm{t}}(\mathrm{L} / \mathrm{detik})
$$

Keterangan :

$\mathrm{Q}=$ debit mataair $(\mathrm{L} /$ detik)

$\mathrm{H}=$ perubahan tinggi muka air $(\mathrm{m})$

$\mathrm{A}=$ luas penampang / bak penampung $\left(\mathrm{m}^{2}\right)$

$\mathrm{t} \quad=$ waktu (detik)

Rumus Manning pengukuran debit digunakan untuk Mataair Kali Lo dan Bulusari karena mataair tersebut merupakan rembesan dan diukur dengan bantuan pelampung pingpong.

$$
\mathrm{Q}=\mathrm{A} \times \mathrm{v}
$$

Keterangan :

$\mathrm{Q}=$ debit mataair $\left(\mathrm{m}^{3} /\right.$ detik)

$\mathrm{A}=$ luas penampang basah $\left(\mathrm{m}^{2}\right)$

$\mathrm{v}=$ rerata kecepatan aliran $(\mathrm{m} /$ detik $)$

Pengambilan sampel air dan pengukuran debit di lapangan dilakukan untuk mengetahui potensi mataair. Pengambilan sampel mataair dilakukan dengan teknik grab sampling yang diambil sesaat untuk mengambil air dari mataair. Pengambilan sampel diambil sesuai standar yang berlaku mengacu pada SNI 6989.57:2008 tentang Metode Pengambilan Contoh Air Permukaan. Uji laboratorium dilakukan untuk parameter yang tidak bisa diukur di lapangan. Hasil pengujian kualitas air merujuk pada Baku Mutu Air Kelas I Peraturan Gubernur DIY No 20 Tahun 2008. Baku mutu parameter air yang diuji terdapat pada Tabel 1. 
12 ISSN 2549-7197 (cetak), ISSN 2549-564X (online)

JMEL, Volume 4 Nomor 2, 2020

Tabel 1. Baku Mutu Parameter yang Diuji

\begin{tabular}{|c|c|c|c|}
\hline No & Parameter & Baku Mutu & Keterangan \\
\hline 1. & Kekeruhan & $50 \mathrm{mg} / \mathrm{L}$ & $\begin{array}{l}\text { Bagi pengolahan air minum secara konvensional, residu } \\
\leq 5000 \mathrm{mg} / \mathrm{L}\end{array}$ \\
\hline 2. & TDS & $1000 \mathrm{mg} / \mathrm{L}$ & \\
\hline 3. & $\mathrm{pH}$ & $6-9$ & $\begin{array}{l}\text { Apabila secara alamiah di luar rentang tersebut, maka } \\
\text { ditentukan berdasarkan kondisi alamiah }\end{array}$ \\
\hline 4. & BOD & $2 \mathrm{mg} / \mathrm{L}$ & \\
\hline 5. & COD & $10 \mathrm{mg} / \mathrm{L}$ & \\
\hline 6. & Nitrat & $10 \mathrm{mg} / \mathrm{L}$ & \\
\hline 7. & Besi & $0,3 \mathrm{mg} / \mathrm{L}$ & $\begin{array}{c}\text { Bagi pengolahan air minum secara konvensional, } \mathrm{Fe} \leq 5 \\
\mathrm{mg} / \mathrm{L}\end{array}$ \\
\hline 8. & Coliform Total & $1000 \mathrm{Jml} / \mathrm{mL}$ & \\
\hline
\end{tabular}

Sumber: Peraturan Gubernur DIY No 20 Tahun 2008

Metode wawancara digunakan untuk mengetahui kebutuhan air domestik berupa masak, minum, MCK, menyiram tanaman, ternak dan lain sebagainya di daerah penelitian. Pengambilan sampel wawancara menggunakan stratified random sampling, yaitu mewawancarai penduduk yang menggunakan mataair berdasarkan jumlah KK menggunakan metode menurut Dixon dan B. Leach dalam Yanuarti, (2014) dapat dilihat pada Persamaan 3 dan Persamaan 4.

Jumlah sampel yang diambil :

$$
\mathrm{n}=\left[\frac{\mathrm{Zx} \mathrm{V}}{\mathrm{C}}\right]^{2}
$$

Keterangan :

$\mathrm{n}=$ Jumlah sampel

$\mathrm{z}=$ Tingkat kepercayaan (confidence level), nilai confidence level $95 \%$ adalah 1,96

$\mathrm{v}=$ Variabilitas $(\%)$ dihitung dengan rumus $: \mathrm{v}=\sqrt{\mathrm{p}(100-\mathrm{p})}$

$\mathrm{p}=$ Presentase karakteristik sampel yang dianggap benar

$\mathrm{c}=$ Batas kepercayaan dalam persen

Jumlah sampel tersebut perlu dikoreksi dengan rumus :

$$
\mathrm{n}^{\prime}=\frac{\mathrm{n}}{1+\frac{\mathrm{n}}{\mathrm{N}}}
$$

Keterangan :

n' = Jumlah sampel yang telah dikoreksi

$\mathrm{n}$ = Jumlah sampel yang dihitung berdasarkan rumus diatas

$\mathrm{N}$ = Jumlah populasi (Kepala Keluarga)

Evaluasi potensi mataair ditinjau berdasarkan kuantitas dan kualitas mataair. Kuanitas mataair didapatkan dari perhitungan debit mataair yang kemudian dibandingkan dengan jumlah kebutuhan air penduduk untuk diketahui kekritisan air di daerah penelitian. Kuantitas mataair untuk 10 tahun didapatkan dari pengukuran langsung debit setiap mataair dengan asumsi debit mataair adalah tetap setiap tahunnya. Besar pertumbuhan penduduk selama 10 tahun ke depan dapat dihitung berdasarkan data persen pertumbuhan penduduk setiap tahunnya. Metode untuk proyeksi jumlah penduduk di suatu wilayah menggunakan Metode Geometrik (bunga berganda) dengan rumus Pn $=$ Po $(1+r)^{n}$, asumsi : laju pertumbuhan penduduk adalah sama untuk setiap tahun, yang artinya pertambahan absolut tiap tahun semakin besar. Indeks kekritisan air merupakan presentase perbandingan antara ketersediaan dan kebutuhan air. Suatu daerah dapat digolongkan kritis apabila perbandingan antara ketersediaan dan kebutuhan airnya melebihi 75\% (Asrifah, 2012).

Hasil evaluasi penelitian akan digunakan untuk acuan dalam menentukan teknik konservasi mataair yang tepat. Konservasi mataair dapat diketahui dari hasil evalusi potensi mataair dan penentuan daerah imbuhan yaitu pengelolaan daerah imbuhan dengan pendekatan vegetatif, pendekatan teknik berupa reservoir dan hidran untuk sistem distribusi air bersih, serta pendekatan sosial institusi. Pengelolaan mataair adalah dengan menentukan kriteria kawasan perlindungan mataair. Penentuan batas kawasan perlindungan mataair mengacu pada Keputusan Presiden Republik Indonesia Nomor 32 Tahun 1990 tentang Pengelolaan Kawasan Lindung. Kawasan sekitar mataair adalah kawasan di sekeliling yang mempunyai manfaat penting untuk mempertahankan kelestarian fungsi mataair. Kriteria garis sempadan kawasan sekitar mataair paling sedikit 200 meter dari mataair. Peraturan tersebut menjelaskan bahwa, perlindungan terhadap kawasan sekitar mataair dilakukan untuk melindungi mataair dari kegiatan budidaya yang dapat merusak kualitas air dan kondisi fisik kawasan sekitarnya. 
Konservasi vegetatif dan mekanik untuk arahan pengelolaan mataair sangat penting untuk membantu menurunkan erosi lahan dengan mengurangi daya rusak oleh hujan, daya rusak aliran permukaan yang meningkatkan pengisian airtanah. Pendekatan teknik yang dapat dilakukan adalah dengan menggunakan reservoir distribusi diantaranya dengan membangun bak penampung dan perancangan sistem pengaliran menjadi yang lebih baik. Perencanaan reservoir dan pembangunan hidran umum mengacu pada Petunjuk Teknis Pelaksanaan Prasarana Air Minum Sederhana Tahun 2007 dalam Peraturan Menteri PU No. 39 Tahun 2006 serta Pedoman Teknis Air Bersih IKK Pedesaan.

\section{HASIL DAN PEMBAHASAN}

Daerah penelitian yang berada di Desa Pagerharjo menggunakan 5 mataair utuk memenuhi kebutuhan domestik yaitu Mataair Tuk Wadang, Kali Lo, Kali Gandu, Kali Bajing dan Bulusari. Evaluasi potensi mataair dilihat berdasarkan kuantitas dan kualitas mataair. Potensi mataair yang didapat akan dibandingkan dengan proyeksi jumlah penduduk pengguna mataair dan kebutuhan air domestik warga selama 10 tahun kedepan. Hasil pengukuran debit mataair di daerah penelitian dapat dilihat pada Tabel 2.

Tabel 2. Hasil Pengukuran Debit Mataair di Daerah Penelitian

\begin{tabular}{|c|c|c|c|c|c|c|}
\hline \multirow[t]{2}{*}{ No } & \multirow[t]{2}{*}{ Bulan } & \multicolumn{5}{|c|}{ Debit (L/detik) } \\
\hline & & Tuk Wadang & Kali Lo & Kali Gandu & Kali Bajing & Bulusari \\
\hline 1 & Februari & 1,925 & 1,650 & 1,150 & 3,153 & 1,029 \\
\hline 2 & Maret & 1,990 & 1,428 & 0,920 & 3,090 & 0,841 \\
\hline 3 & April & 1,284 & 0,889 & 0,307 & 2,712 & 0,513 \\
\hline 4 & Mei & 1,155 & 0,823 & 0,199 & 1,892 & 0,259 \\
\hline 5 & Juni & 0,128 & 0,244 & 0,575 & 1,072 & 0,091 \\
\hline 6 & November & 0,025 & 0,000 & 0,007 & 0,315 & 0,005 \\
\hline \multicolumn{2}{|c|}{ Rata-rata (L/detik) } & 1,085 & 0,839 & 0,526 & 2,039 & 0,456 \\
\hline
\end{tabular}

Sumber: Hasil Pengolahan Data Primer, 2019

Penentuan parameter yang akan diuji berdasarkan keadaan lingkungan di daerah penelitian. Nilai kekeruhan dan TDS diambil karena mataair di daerah penelitian tidak ditutup dan dibiarkan terbuka sehingga zat pengotor mudah tercampur dengan air tersebut. Parameter BOD dan COD diambil untuk mengetahui perkiraan jumlah bahan organik yang terkandung di mataair tersebut. Parameter nitrat diambil karena mataair yang tidak tertutup memiliki kemungkinan terjadi penambahan kandungan nitrat yang berasal dari tumbuhan atau hewan yang mati serta adanya hujan yang membawa sejumlah nitrogen. Parameter besi diambil karena proses vulkanisme yang membentuk daerah penelitian diasumsikan memiliki kandungan besi yang tinggi. Hasil uji laboratorium kualitas air di mataair dapat dilihat pada Tabel 3.

Tabel 3. Hasil Uji Laboratorium Kualitas Air Mataair di Daerah Penelitian

\begin{tabular}{|c|c|c|c|c|c|c|c|}
\hline \multirow[t]{2}{*}{ Parameter } & \multirow[t]{2}{*}{ Baku Mutu } & \multirow[t]{2}{*}{ Satuan } & \multicolumn{5}{|c|}{ Mataair } \\
\hline & & & $\begin{array}{c}\text { Tuk } \\
\text { Wadang }\end{array}$ & Kali Lo & $\begin{array}{c}\text { Kali } \\
\text { Gandu }\end{array}$ & $\begin{array}{c}\text { Kali } \\
\text { Bajing }\end{array}$ & Bulusari \\
\hline Kekeruhan & 50 & $\mathrm{mg} / \mathrm{L}$ & 0,4 & 0,5 & 0,4 & 0,6 & 0,5 \\
\hline TDS & 1000 & $\mathrm{mg} / \mathrm{L}$ & 106 & 122 & 206 & 180 & 137 \\
\hline pH & $6-9$ & & 6,3 & 6,2 & 6,6 & 6,7 & 6,3 \\
\hline BOD & 2 & $\mathrm{mg} / \mathrm{L}$ & 0,7 & 1,5 & 0,6 & 0,4 & 1,1 \\
\hline COD & 10 & $\mathrm{mg} / \mathrm{L}$ & 3,6 & 15,4 & 3,6 & 3,6 & 11,7 \\
\hline Nitrat & 10 & $\mathrm{mg} / \mathrm{L}$ & 1,79 & 2,62 & 3,59 & 1,99 & 2,75 \\
\hline Besi & 0,3 & $\mathrm{mg} / \mathrm{L}$ & 0,0162 & 0,0162 & 0,0162 & 0,0162 & 0,0162 \\
\hline Coliform Total & 1000 & $\mathrm{Jml} / \mathrm{mL}$ & 1700 & 2400 & 2400 & 540 & 1600 \\
\hline
\end{tabular}

Sumber: Hasil Pengolahan Data Primer, 2019

Mataair di daerah penelitian telah memenuhi baku mutu kualitas air untuk beberapa parameter. Terdapat dua mataair yang melebihi baku mutu parameter COD. Tingginya COD pada kedua mataair ini menandakan banyaknya jumlah bahan organik sulit urai yang ada (Atima, 2014) yang mana dapat dilihat dari selisih nilai BOD dan COD pada kedua mataair, yaitu pada Mataair Kali Lo jumlah bahan organik sulit urai 13,9 mg/L dan pada Mataair Bulusari 10,6 mg/L. Hasil uji laboratorium menunjukkan bahwa keempat mataair di daerah penelitian melebihi baku mutu untuk parameter coliform total. Mataair Tuk Wadang berada pada kolam besar yang tidak tertutup dan berada pada tengah kebun, sehingga hewan liar dan kotoran dapat mudah masuk. Mataair Kali Lo dan Bulusari muncul sebagai rembesan dan belum dibuat tampungan air. Mataair Kali Gandu berada di dekat permukiman yang saluran pembuangannya mengarah ke dekat mataair. Mataair Kali Bajing sudah memiliki tampungan lebih baik dari mataair lainnya sehingga pengotor tidak mudah masuk. Potensi mataair dilihat dari kualitas mataair akan semakin menurun seiring dengan pertumbuhan 


\section{ISSN 2549-7197 (cetak), ISSN 2549-564X (online) JMEL, Volume 4 Nomor 2, 2020}

penduduk karena terjadinya pembangunan di daerah imbuhan atau sekitar mataair yang akan mencemari mataair dari limbah yang dibuang.

Evaluasi kebutuhan air dilakukan dengan wawancara kepada warga yang menggunakan mataair di daerah penelitian tentang kebutuhan air domestik setiap harinya. Hasil kebutuhan warga kemudian dikalkulasikan sehingga didapatkan kebutuhan perorang perhari. Jumlah penggunaan air pada mataair yang diteliti dapat dilihat pada Tabel 4.

Tabel 4. Hasil Uji Laboratorium Kualitas Air Mataair di Daerah Penelitian

\begin{tabular}{|c|c|c|c|c|c|}
\hline \multirow[t]{2}{*}{ Mataair } & \multicolumn{2}{|c|}{ Jumlah Pengguna } & \multicolumn{2}{|c|}{ Jumlah Responden } & \multirow{2}{*}{$\begin{array}{l}\text { Penggunaan air } \\
\text { (L/hari/orang) }\end{array}$} \\
\hline & (KK) & (Orang) & (KK) & (Orang) & \\
\hline Tuk Wadang & 28 & 90 & 12 & 41 & 64,585 \\
\hline Kali Lo & 7 & 21 & 3 & 11 & 64,545 \\
\hline Kali Gandu & 44 & 140 & 19 & 70 & 66,621 \\
\hline Kali Bajing & 21 & 84 & 9 & 38 & 69,197 \\
\hline Mataair Bulusari & 5 & 15 & 2 & 5 & 64,6 \\
\hline
\end{tabular}

Sumber: Hasil Pengolahan Data Primer, 2019

Potensi kelima mataair dilihat pada musim penghujan dan musim kemarau ketika pengukuran debit dilakukan. Debit mataair pada musim kemarau akan menurun dan pada mataair Kali Lo mengalami kekeringan. Penurunan debit air ini menyebabkan penggunaan air warga pada musim kemarau harus dikurangi dan pemanfaatannya dilakukan secara bergantian. Selain itu pemenuhan kebutuhan air warga diperoleh dari mataair di dusun lain dan memanfaatkan air sungai. Gambar 2. menunjukkan grafik kekritisan air kelima mataair tahun 2019 hingga 2029. Grafik tersebut menunjukkan bahwa daerah penelitian belum mengalami kekritisan air karena indeks kekritisan air dibawah $75 \%$. Indeks kekritisan Kali Lo, Kali Bajing dan Bulusari relatif seragam. Indeks kekritisan Tuk Wadang dan Kali Gandu lebih tinggi dari tiga matair lainnya karena penggunanya lebih banyak yaitu Tuk Wadang 90 jiwa dan Kali Gandu 140 jiwa.

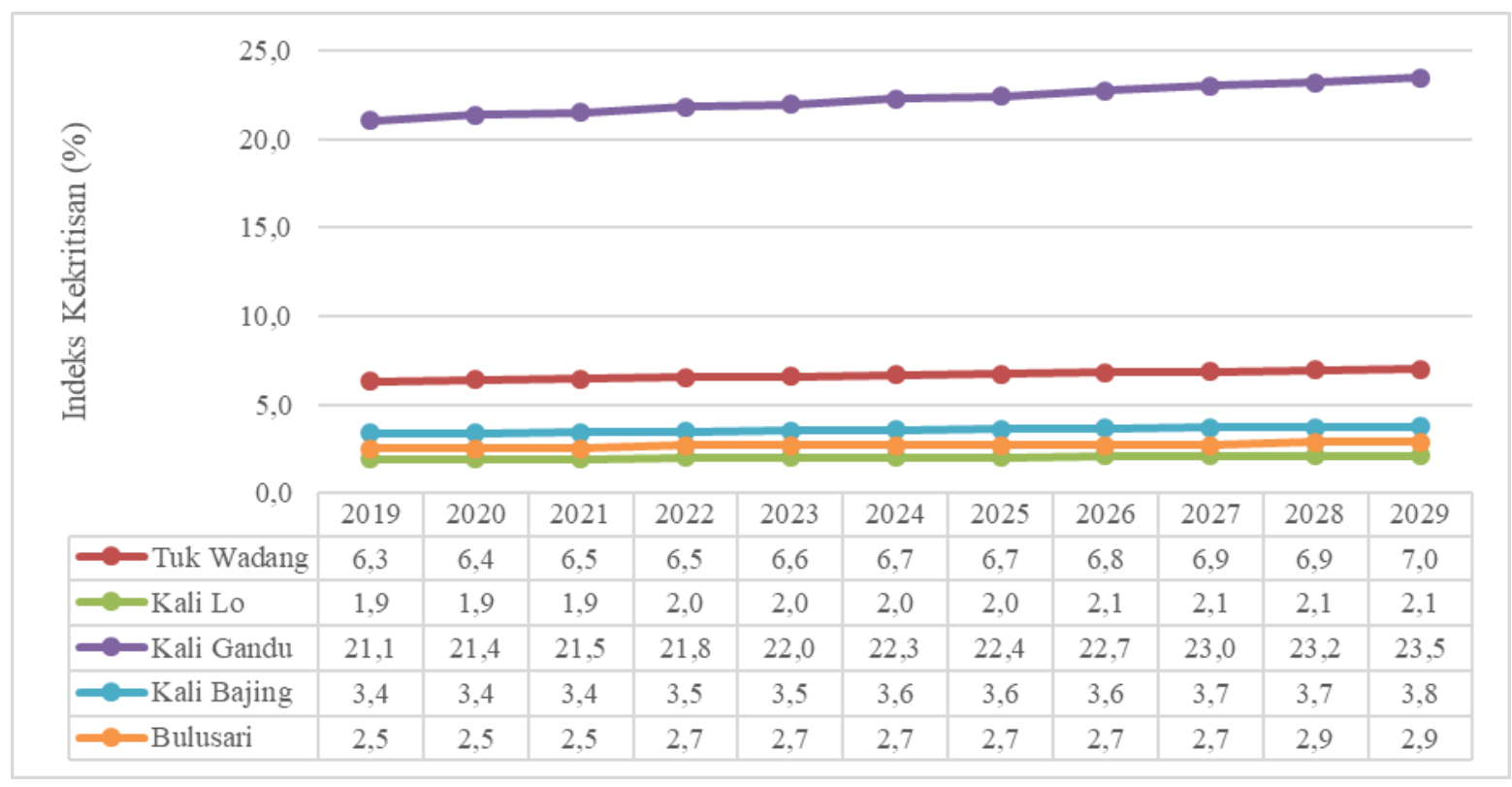

Gambar 2. Grafik Indeks Kekritisan Mataair di Desa Pagerharjo (Sumber: Pengukuran Penulis)

Arahan konservasi mataair di daerah penelitian perlu dilakukan untuk menjaga kuantitas, kualitas dan keberlanjutan ketersediaan mataair dalam bentuk konservasi teknis dan non teknis dengan pendekatan masyarakat (sosial) dan institusi (pemerintah). Konservasi daerah imbuhan pada daerah penelitian dapat dilakukan dengan pembuatan teras individu. Teras individu dipilih karena teras ini sesuai pada lahan dengan kemiringan lereng terjal. Teras ini cocok untuk tanaman perkebunan tanpa melakukan land clearing pada tanaman yang sudah ada. Tinggi teras dan lebar bidang olah dapat disesuaikan dengan tanaman yang sudah ada di daerah penelitian. Area pada bidang olah yang kosong perlu ditanami rumput gajah paitan (Axonopus compressus ( $S w$. .) Beauv) sebagai pengontrol erosi dan memiliki tingkat pemeliharaan rendan dengan sedikit tekanan (Andhina, 2007). Pembuatan teras pada daerah imbuhan dapat menambah daerah tangkapan air untuk mengoptimalkan kemampuan infiltrasi daerah penelitian. Arahan konservasi mataair di daerah penelitian dapat dilihat pada Gambar 3. 
Konservasi non-teknis daerah imbuhan dilakukan dengan cara pendekatan kepada masyarakat di sekitar daerah imbuhan, antara lain penyuluhan kepada masyarakat tentang kesadaran pelindungan dan pengelolaan lingkungan hidup di daerah imbuhan; pembatasan pertambahan bangunan di daerah imbuhan karena dapat mempengaruhi kuantitas dan kualitas mataair; penyuluhan kepada masyarakat di daerah imbuhan bahwa harus menjaga kelestarian di permukimannya dengan penanaman pohon; dan penyuluhan kepada masyarakat untuk mengurangi pembuangan limbah domestik langsung ke tanah atau dengan pengolahan air limbah sederhana sebelum dibuang ke tanah.

Konservasi teknis mataair digunakan untuk menjaga kuantitas dan kualitas mataair dari daya rusak air. Konservasi teknis dilakukan dengan pembuatan prasarana berupa bangunan penangkap mataair, bak penampung mataair dan sistem perpipaan terhadap masyarakat yang menggunakan mataair. Ketentuan bangunan penangkap sesuai dengan Lampiran $\mathrm{V}$ Modul Perlindungan Mataair Permen PU 01/PRT/M/2009 mataair gravitasi dengan tipe 1A. Pembangunan bak penampung mataair disesuaikan dengan debit mataair dan kebutuhan air masyarakat berdasarkan Lampiran V Modul Perlindungan Mataair Permen PU 01/PRT/M/2009. Berdasarkan debit dan pengguna mataair, kapasitas bak penampung Mataair Tuk Wadang, Kali Lo, Kali Bajing dan Bulusari adalah $2 \mathrm{~m}^{3}$ sedangkan untuk Mataair Kali Gandu $5 \mathrm{~m}^{3}$. Lokasi pembangunan bak penangkap disesuaikan dengan Kepres RI No. 32 Tahun 1990 Tentang Pengelolaan Kawasan Lindung, yaitu garis sempadan mataair paling sedikit 200 meter dari mataair

Konservasi mataair secara non-teknis dilakukan dengan cara pendekatan kepada masyarakat sekitar mataair, antara lain penyuluhan kepada masyarakat tentang kesadaran pelindungan dan pengelolaan lingkungan hidup di sekitar mataair; penambahan pengetahuan dan wawasan sejak dini tentang pentingnya menjaga kelestarian sumber daya air; penyuluhan kepada masyarakat untuk melakukan pemeliharaan rutin sarana dan prasarana mataair yang dapat dikerjakan secara gotong-royong dan bergantian; dan pembuatan poster himbauan kepada masyarakat sekitar mataair dan pengunjung yang memanfaatkan mataair.

Pendekatan sosial juga dilakukan pada warga pengguna mataair, antara lain penyuluhan kepada masyarakat pengguna mataair tentang penggunaan air secara efektif dan efisien serta tidak berlebihan; melakukan musyawarah warga untuk mengantisipasi terjadinya kekeringan di daerah penelitian, dengan mencari alternative lain untuk pemenuhan kebutuhan air; pengetahuan kepada warga untuk menghindari konflik dalam penggunaan air; dan sosialisasi untuk pengadaan tempat penampungan air di masing-masing rumah untuk menanggulangi kekurangan air ketika musim kemarau.

Pemerintah memiliki pengaruh besar untuk menggerakkan masyarakat dalam upaya pengelolaan mataair. Pendekatan pemerintah antara lain memperhatikan tata wilayah di daerah penelitian, berupa penggunaan lahan yang ada di daerah imbuhan, apabila ada yang menurunkan kemampuan daerah imbuhan dapat dilakukan pertimbangan ulang dan perbaikan; penyuluhan oleh pemerintah kepada masyarakat tentang penjagaan kawasan lindung mataair berupa daerah sempadan dan daerah imbuhan yang tidak boleh ada kegiatan manusia; perbaikan sarana dan prasarana penunjang mataair; dan perawatan dan pengecekan menyeluruh secara rutin, baik dari sisi kualitas dan kuantitas serta sarana prasarana yang ada. 

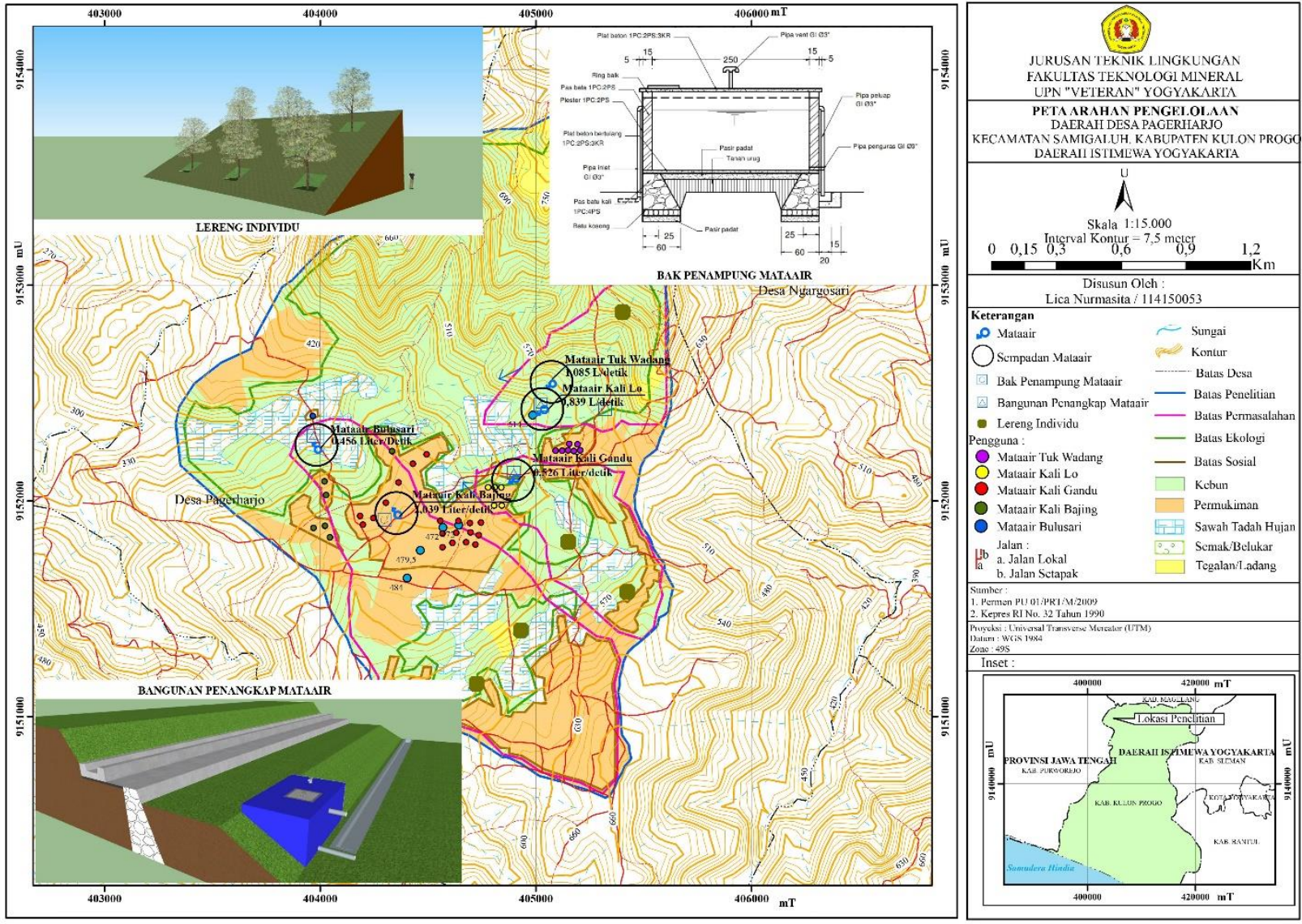

Gambar 3. Peta Arahan Pengelolaan Daerah Penelitian

\section{KESIMPULAN}

1. Debit mataair di daerah penelitian memenuhi kebutuhan pengguna seiring dengan pertumbuhan penduduk hingga 10 tahun kedepan. Kualitas mataair cukup baik pada beberapa parameter namun melebihi baku mutu untuk parameter COD pada Mataair Kali Lo dan Bulusari serta parameter coliform total pada Mataair Tuk Wadang, Kali Lo, Kali Gandu dan Bulusari. Kualitas air menurun seiring pertumbuhan penduduk tetapi dapat diatasi dengan arahan konservasi.

2. Arahan konservasi daerah imbuhan adalah dengan pembuatan teras individu dan penanaman rumput gajah paitan (Axonopus compressus $(S w$.$) Beauv) serta penyuluhan kepada masyarakat. Arahan konservasi mataair secara$ teknis antara lain dengan pembuatan bangunan penangkap mataair dan bak penampung dengan kapasitas $2 \mathrm{~m}^{3}$ (Tuk Wadang, Kali Lo, Kali Bajing, Bulusari) dan $5 \mathrm{~m}^{3}$ (Kali Gandu) dan penyuluhan kepada masyarakat sekitar mataair. Arahan konservasi dilaksanakan dengan pendekatan sosial kepada masyarakat pengguna mataair dan pendekatan institusi kepada pemerintah.

\section{DAFTAR PUSTAKA}

Admadhani, D. N., Haji, A. T. S., \& Susanawati, L. D. (2014). Analisis Ketersediaan dan Kebutuhan Air untuk Daya Dukung Lingkungan (Studi Kasus Kota Malang). Jurnal Sumberdaya Alam dan Lingkungan, 1(3), 13-20.

Andhina, Ayuningtyas. (2007). Kajian Kualitas Rumput Lapangan Sepakbola di Jakarta dan Bogor (Skripsi). Institut Pertanian Bogor, Bogor.

Asrifah, D. (2013). Evaluasi Potensi Airtanah Bebas untuk Penyediaan Air di Kalasan dan Prambanan. Majalah Geografi Indonesia, 27(1), 56-78. Diakses pada 16 November 2019

Atima, W. (2015). BOD dan COD sebagai parameter pencemaran air dan baku mutu air limbah. BIOSEL (Biology Science and Education): Jurnal Penelitian Science dan Pendidikan, 4(1), 83-93. Diakses pada 27 Februari 2019

Efendi, M., Sunoko, H. R., \& Sulistya, W. (2012). Kajian Kerentanan Masyarakat terhadap Perubahan Iklim Berbasis Daerah Aliran Sungai (Studi Kasus Sub DAS Garang Hulu). Jurnal Ilmu Lingkungan, 10(1), 8-18. Diakses pada 23 Februari 2019 
Keputusan Presiden Republik Indonesia Nomor 32 Tahun 1990 tentang Pengelolaan Kawasan Lindung.

Peraturan Gubernur DIY No. 20 Tahun 2008 tentang Baku Mutu Air di Provinsi Daerah Istimewa Yogyakarta.

Peraturan Menteri Pekerjaan Umum 01/PRT/M/2009 tentang Penyelenggaraan Pengembangan SPAM Bukan Jaringan Perpipaan.

Peraturan Menteri Pekerjaan Umum No. 18 Tahun 2007 tentang Penyelenggaraan Pengembangan Sistem Penyediaan Air Minum

Peraturan Menteri Pekerjaan Umum Nomor 39 Tahun 2006 tentang Petunjuk Teknis Penggunaan Dana Alokasi Khusus Bidang Infastruktur Tahun 2007.

Rasmikayati, E., \& Djuwendah, E. (2015). Dampak Perubahan Iklim terhadap Perilaku dan Pendapatan Petani (The Impact of Climate Change to Farmers' Behavior and Revenue). Jurnal Manusia Dan Lingkungan, 22(3), 372379. Diakses pada 23 Februari 2019

SNI 6989.57:2008 tentang Air dan Air Limbah - Bagian 57: Metode Pengambilan Contoh Air Permukaan.

Yanuarti, A.S. (2014). Kajian Terhadap Kebutuhan dan Upaya Pemenuhan Air Bersih di Kelurahan Pasir Impun, Kecamatan Mandalajati Kota Bandung (Skripsi). Universitas Pendidikan Indonesia, Bandung. 